\title{
Adult-onset non-5q proximal spinal muscular atrophy: a comprehensive review
}

\author{
Atrofia muscular espinhal não-5q proximal de início no adulto: uma revisão abrangente \\ Wladimir Bocca Vieira de Rezende PINTO', Paulo Victor Sgobbi de SOUZA¹, Bruno Mattos Lombardi BADIA', \\ Igor Braga FARIAS', José Marcos Vieira de ALBUQUERQUE FILHO'1, Eduardo Augusto GONÇALVES', \\ Roberta Ismael Lacerda MACHADO', Acary Souza Bulle OLIVEIRA'
}

\begin{abstract}
Background: Adult-onset spinal muscular atrophy (SMA) represents an expanding group of inherited neurodegenerative disorders in clinical practice. Objective: This review aims to synthesize the main clinical, genetic, radiological, biochemical, and neurophysiological aspects related to the classical and recently described forms of proximal SMA. Methods: The authors performed a non-systematic critical review summarizing adult-onset proximal SMA presentations. Results: Previously limited to cases of SMN1-related SMA type 4 (adult form), this group has now more than 15 different clinical conditions that have in common the symmetrical and progressive compromise of lower motor neurons starting in adulthood or elderly stage. New clinical and genetic subtypes of adult-onset proximal SMA have been recognized and are currently target of wide neuroradiological, pathological, and genetic studies. Conclusions: This new complex group of rare disorders typically present with lower motor neuron disease in association with other neurological or systemic signs of impairment, which are relatively specific and typical for each genetic subtype.
\end{abstract}

Keywords: Muscular Atrophy, Spinal; Neurodegenerative Diseases; Motor Neuron Disease; Neuromuscular Diseases.

\section{RESUMO}

Antecedentes: Atrofia muscular espinhal (AME) de início no adulto representa um grupo de doenças neurodegenerativas hereditárias em expansão na prática clínica. Objetivo: Este artigo de revisão sintetiza os principais aspectos clínicos, genéticos, radiológicos, bioquímicos e neurofisiológicos relacionados às formas clássicas e recentemente descritas de AME proximal do adulto. Métodos: Os autores realizaram uma revisão crítica não sistemática descrevendo as principais apresentações de AME proximal de início no adulto. Resultados: Previamente restrito às apresentações de AME tipo 4 associada ao gene SMN1, este grupo atualmente envolve mais de 15 diferentes condições clínicas que compartilham entre si a presença de comprometimento progressivo e simétrico do neurônio motor inferior se iniciando no adulto ou no idoso. Novos subtipos clínicos e genéticos de AME proximal de início no adulto foram reconhecidas e são alvos atuais de estudos direcionados a aspectos neurorradiológicos, patológicos e genéticos. Conclusões: Este novo grupo complexo de doenças raras tipicamente se apresenta com doença do neurônio motor inferior em associação com outros sinais de comprometimento neurológico ou sistêmico, os quais apresentam padrões relativamente específicos para cada subtipo genético.

Palavras-chave: Atrofia Muscular Espinhal; Doenças Neurodegenerativas; Doença dos Neurônios Motores; Doenças Neuromusculares.

\section{INTRODUCTION}

Motor neuron disease (MND) represents a wide and expanding group of different neurological disorders resulting from isolated or combined involvement of lower and upper motor neurons. The main adult-onset clinical disorder in this group is amyotrophic lateral sclerosis (ALS) ${ }^{1}$, however there is a high number of sporadic and hereditary neurological diseases that may present with MND phenotype and should be considered in the differential diagnosis (Table 1) 1,3,4 $^{2}$.

\footnotetext{
${ }^{1}$ Universidade Federal de São Paulo, Departamento de Neurologia e Neurocirurgia, Setor de Investigações nas Doenças Neuromusculares, São Paulo SP, Brazil. WBVRP (iD https://orcid.org/0000-0002-0150-525X; PVSS (iD https://orcid.org/0000-0002-7416-7108; BMLB iD https://orcid.org/0000-0001-7360-0494; IBF (iD) https://orcid.org/0000-0003-2187-6573;JMVAF (D) https://orcid.org/0000-0002-4533-2637; EAG (iD https://orcid.org/0000-0002-9893-2468; RILM (iD) https://orcid.org/0000-0002-5842-0062; ASBO (iD https://orcid.org/0000-0002-6986-4937

Correspondence: Wladimir Bocca Vieira de Rezende Pinto; Email:wladimirbvrpinto@gmail.com.

Conflict of interest: There is no conflict of interest to declare.

Authors' contributions: WBVRP: conception, organization, and execution of manuscript project, writing of the first draft, and review and critique of manuscript; PVSS, EAG: conception, organization, and execution of manuscript project, writing of the first draft of manuscript; BMLB, JMVAF, RILM: conception, and organization of manuscript project, writing of the first draft of manuscript; IBF, ASBO: conception of manuscript project, writing of the first draft, review and critique of manuscript.

Received on September 05, 2020; Received in its final form on January 31, 2020; Accepted on December $24,2020$.
} 
Table 1. Classification of primary adult- and childhood-onset motor neuron disease $e^{1,2,3,4,7}$.

\begin{tabular}{l} 
Classification of Motor Neuron Disease (MND) group* \\
Upper and lower MND \\
Amyotrophic Lateral Sclerosis (ALS) (sporadic, familial; \\
juvenile) \\
Mills'syndrome (progressive hemiplegic variant)** \\
Upper MND \\
Primary Lateral Sclerosis (PLS) (sporadic, familial) \\
Lower MND \\
Progressive Muscular Atrophy (Duchenne-Aran syndrome) \\
(sporadic) \\
SMN1-associated (5q) Spinal Muscular Atrophy (SMA) \\
(hereditary) \\
Non-5q (non-SMN1/SMN2) SMA (familial, hereditary) \\
Distal SMA (distal hereditary motor neuronopathy) \\
Proximal non-5q SMA \\
"Flail-arm" syndrome (Vulpian-Bernhardt) (sporadic, familial) \\
O'Sullivan-McLeod syndrome (sporadic) \\
Hirayama disease (Juvenile monomelic distal amyotrophy) \\
(sporadic) \\
"Flail-leg" syndrome (pseudopolyneuritic form) (sporadic) \\
MND with marked bulbar and cranial nerve involvement \\
Progressive Bulbar Palsy (sporadic) \\
Kennedy's disease (X-linked spinal and bulbar muscular \\
atrophy) (familial, hereditary) \\
Fazio-Londe disease (Juvenile Progressive Bulbar Palsy) \\
(sporadic, familial) \\
Brown-Vialetto-van Laere syndrome (sporadic, familial) \\
Madras MND (sporadic, familial) \\
FOSMN syndrome*** (sporadic, familial) \\
\hline
\end{tabular}

ALS: amyotrophic lateral sclerosis; FOSMN: facial-onset sensory and motor neuronopathy; MND: motor neuron disease; PLS: primary lateral sclerosis. *Primary MND group includes distinct clinical conditions which result from primary compromise and neurodegeneration of the lower and/ or upper motor neurons; **the classification of Mills' syndrome as an ALS or PLS variant is still a matter of debate; ${ }^{* \star} \mathrm{FOSMN}$ is currently included in the group of primary MND, despite its rare occurrence, due to the major neuropathological, laboratory, and neuroimaging evidence linking to ALS-like phenotype and biomarkers.

Spinal Muscular Atrophy (SMA) is the most common group of inherited motor neuronopathies in clinical practice and can present in a wide range of patients including pediatric cases (e.g., neonatal and infancy onset) to late-onset cases (e.g., elderly and adult onset cases) $)^{5,6}$. SMA represents a group of inherited neurodegenerative, neurodevelopmental, or neurometabolic disorders that leads to lower motor neuron impairment in a pure pattern (sparing other multisystemic and neurological involvement) or in association with other neurological and multisystemic involvement (SMA-plus or complex phenotypes) $)^{5,6}$. The SMN1-related SMA (also designated as 5q SMA) comprises the most important clinical and genetic form of SMA, representing the second most common autosomal recessive disorder in clinical practice and including type 1 (Werdnig-Hoffmann disease), type 2 (intermediate or Dubowitz syndrome), type 3 (Kugelberg-Welander disease), and type 4 (adult type) ${ }^{5,6}$. It is estimated a global prevalence of 1 in 10.000 and a carrier incidence of 1 in 50 in the general population ${ }^{5,6}$.
Adult-onset SMA represents a new expanding group of inherited neurodegenerative disorders in clinical practice in the context of late-onset lower MND with pure motor phenotypes or complex systemic and neurological phenotypes. In adult-onset cases, SMA type 4 is the most common type of proximal SMA, and the differential diagnosis with youngonset and juvenile ALS ${ }^{7}$ and with non-5q (non-SMN1) SMA is important. The non-5q (non-SMN1) SMA is an expanding and complex group of more than 15 different clinical and genetic conditions and the target of this review manuscript $^{3,8}$. Proper evaluation and diagnosis of such group of diseases is essential as many of them present as specific potentially treatable conditions that can improve motor and non-motor symptoms, signs, and outcomes. This nonsystematic informative and descriptive critical review aims to summarize the most important clinical, genetic, neurophysiologic, and therapeutic aspects about the well-known and established genetic subtypes of adult-onset proximal non-5q SMA.

We have performed a non-systematic review including two distinct strategies using the National Library of Medicine, PubMed search database [last accessed on $28^{\text {th }}$ January, 2021], with no delineated period or interval of publication on MEDLINE journals and only including adult patients (with 19 or more years of age). The first search strategy included the Medical Subject Headings (MeSH) term [spinal muscular atrophy] and resulted in 9041 manuscripts, including case reports, editorials, historical articles, journal articles, letters, and reviews. Systematic review and meta-analysis studies were excluded. The first evaluation excluding distalpredominant phenotypes, natural history, therapy-related (experimental) studies and redundant content resulted in 152 manuscripts with significant content regarding proximal SMA presentations with clinical, genetic, and therapeutic purposes. The second parallel search strategy used the term [non-5q spinal muscular atrophy] and included case reports, journal articles, letters, and reviews in adult patients resulting in 18 manuscripts, all of which were previously included in the first search strategy. After a detailed review of the content published in the last 5 years, 13 distinct genetic presentations of non-5q SMA have been identified and are discussed in detail in this review article.

\section{NON-5Q PROXIMAL SPINAL MUSCULAR ATROPHY}

Non-5q SMA is an expanding and heterogeneous group of lower MND due to complex clinical and genetic aspects

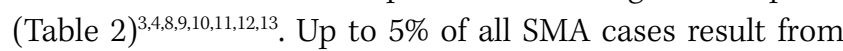
genetic abnormalities in genes other than $S M N 1^{14}$ and are currently included in this group. Research in the last 20 years resulted in a major expansion in knowledge regarding clinical, pathophysiological, and genetic aspects of different non-5q SMA, especially in the early-onset forms ${ }^{3,4,8,9,10,11,12}$. 
Table 2. Current classification of adult-onset spinal muscular atrophy with proximal predominance, according to the involved pattern of inheritance $e^{3,4,6,8,9,10,11,12,14}$.

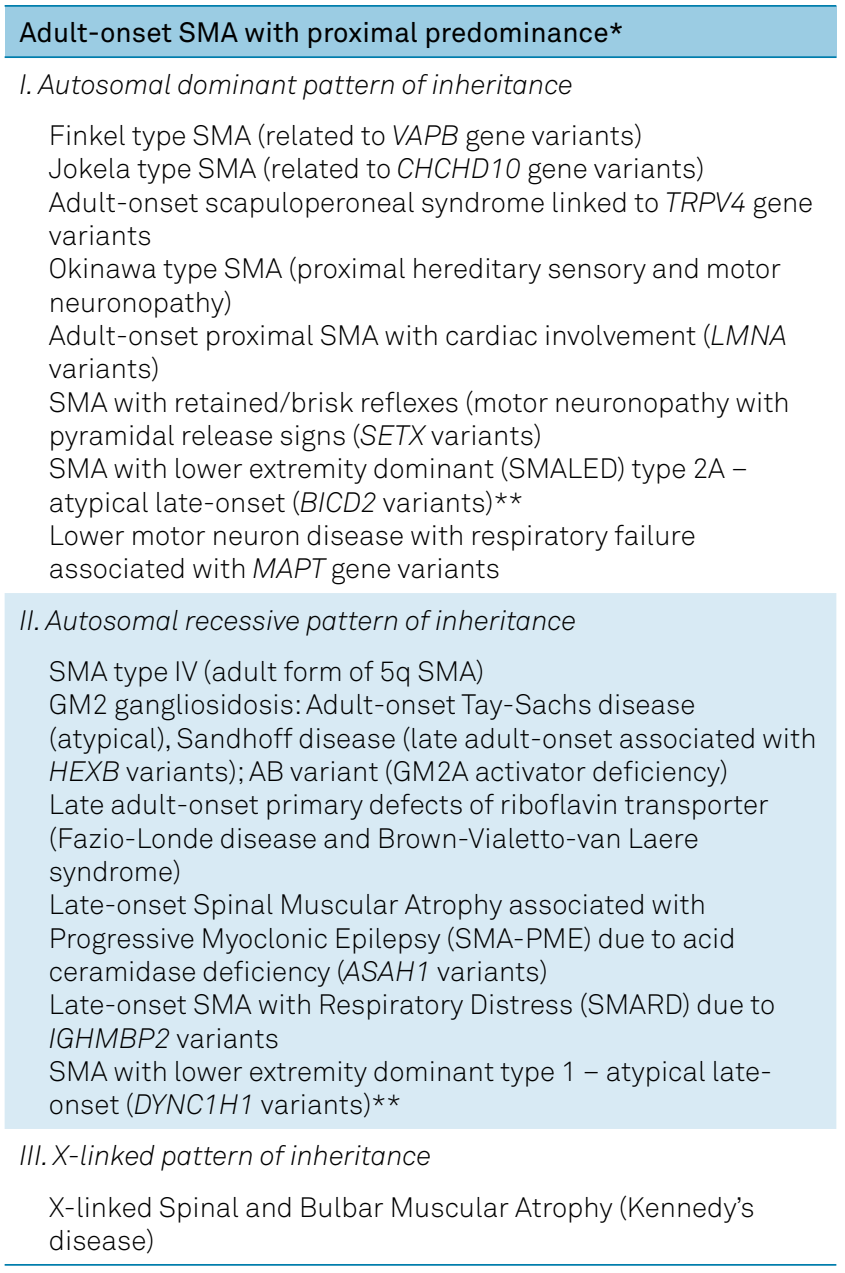

SMALED: spinal muscular atrophy with lower extremity predominance; * distal SMA [spinal muscular atrophy] (or distal hereditary motor neuronopathy) presentations are not included; $* \star$ limited data restricted to case reports or small case series.

Most of the new genetic subtypes have been identified during genetic evaluation by whole-exome sequencing (WES) and gene panel testing by next-generation sequencing (NGS) approaches ${ }^{13}$.

Non-5q SMA are commonly classified according to the pattern of inheritance and dominant distribution pattern of weakness (distal SMA, also called distal hereditary motor neuropathy, proximal non-5q SMA, or bulbar-dominant SMA). Adult-onset non-5q SMA can present with two different clinical pictures including: (i) patients with late-onset SMA (slowly progressive lower MND) and negative genetic result for $S M N 1 / S M N 2$ gene (pure SMA phenotype); and (ii) autosomal dominant, recessive, or X-linked SMA with other well-defined complex multisystemic or neurological features, including epilepsy, deafness, cerebellar ataxia, or skeletal abnormalities (Table 3) ${ }^{11,12,14}$. This review emphasizes clinical and genetic aspects of adult-onset non-5q proximal SMA (Tables 3 and 4).
Table 3. Red-flag signs to consider a possible non-5q (nonSMN1/SMN2) form of spinal muscular atrophy 11,12,14.

\section{Red-flag signs for a non- $5 q$ SMA presentation}

Disproportionate distal to proximal motor compromise, even in the context of a marked proximal involvement (context of distal hereditary motor neuronopathy — distal SMA)

Specific findings and neurological contexts: arthrogryposis multiplex congenita, vocal cord palsy, diaphragmatic palsy with severe early-onset acute respiratory failure, multiple cranial nerve palsy, progressive myoclonic epilepsy, sensorineural hearing loss, mild pyramidal release signs (similar phenotypes to ALS)

Abnormal findings in neuroimaging studies: pontocerebellar hypoplasia, hypomyelination, leukodystrophy, malformations of central nervous system due to abnormal development

Specific neuroophthalmological findings (e.g. cataracts, optic atrophy, retinitis pigmentosa)

Other specific systemic findings (e.g. cardiomyopathy, endocrinopathy)

Familial spectrum of neurological or systemic compromise associated with other red-flag signs for a possible non-5q SMA

SMA: spinal muscular atrophy; ALS: amyotrophic lateral sclerosis.

The main pathophysiological mechanisms related to non-5q SMA involve different complex intracellular dysfunctions (Figure 1), including: (i) defects of neuronal splicing, DNA and protein translation and transcription, and RNA processing and toxic RNA species formation (e.g., VRK1, EXOSC3, EXOSC8, TSEN54, SLC25A6, MORC2, TRIP4, ASCC1, UBA1, GLE1, ERBB3, IGHMBP2, RBM28); (ii) defects of pathways of protein aggregation, misfolding, and degradation (regulation of protein quality control, autophagy, and ubiquitin-proteasome system) (e.g., ASAH1, UBA1, UBQLN1, LYST, SCP2); (iii) defects of axonal transport and cytoskeletal dynamics (e.g., ASAH1, BICD2, DYNC1H1) by distinct mechanisms; (iv) primary defects of ion channels (cation channeling) (e.g., TRPV4, SCN1A); (v) primary defects of vitamin receptors (uptake) (e.g., SLC52A2, SLC52A3); and (vi) dysfunction of neuronal mitochondrial energy production and inner structure (functional and structural mitochondrial abnormalities) (e.g., CHCHD10, SCO2, TK2, DGUOK) $)^{3,8,9,10,11}$. Inherited neurometabolic disorders are also associated with non-5q SMA presentations, including abnormal sphingolipid metabolism, such as in GM2 gangliosidosis and acid ceramidase deficiency ${ }^{12}$.

\section{Kennedy's disease}

In 1968, Kennedy and colleagues described 9 male patients from 2 unrelated families presenting with slowly progressive pure lower MND with onset between 30 to 40 years of age, disclosing bulbar signs (dysphagia, dysphonia, and tongue atrophy and fasciculation), facial and perioral fasciculations and some of them with bilateral gynecomastia ${ }^{15}$. Endocrinopathies and hyperlipoproteinemia were identified in further studies. 
Table 4. Clues in the differential diagnosis of suspected genetic basis of proximal spinal muscular atrophy $y^{3,9,10,11,12,14}$.

\begin{tabular}{|c|c|}
\hline \multicolumn{2}{|c|}{ Clinical, neuroimaging and laboratorial clues in the evaluation of suspected proximal SMA } \\
\hline I. Age at onset & $\begin{array}{l}\text { Very early (neonatal or infancy-onset; <2 years): SMN1, SLC52A2, SLC52A3, GLE1, VRK1, GLE1, UBA1, } \\
\text { EXOSC8, EXOSC3, TK2*, TRPV4 } \\
\text { Early (early and late childhood-onset): SMN1, DYNC1H1, BICD2, TRPV4, SLC52A2, SLC52A3, ASAH1, } \\
\text { LAS1L, TRPV4 } \\
\text { Late (juvenile and adult-onset): SMN1, VAPB, TFG, AR, LMNA, SETX, CHCHD10, HEXA, HEXB, GM2A, } \\
\text { TRPV4*, ASAH1*, SLC52A2*, SLC52A3*, BICD2*, DYNC1H1* }\end{array}$ \\
\hline II. Pattern of inheritance & $\begin{array}{l}\text { AR: SMN1, SLC52A2, SLC52A3, HEXA, HEXB, GM2A, ASAH1, VRK1, EXOSC3, EXOSC8, GLE1, IGHMBP2 } \\
\text { AD:VAPB, TRPV4, TFG, CHCHD10, SETX, LMNA, DYNC1H1, BICD2, GLE1 } \\
\text { XLR:AR, UBA1, LAS1L }\end{array}$ \\
\hline III. LGMW phenotype & $\begin{array}{l}\text { Lower extremity predominance: DYNC1H1, BICD2, SMN1, VAPB } \\
\text { Scapuloperoneal pattern: TRPV4, SLC52A3* } \\
\text { Moderate/severe axial involvement: SMN1,VRK1, AR, SLC52A2*, SLC52A3* }\end{array}$ \\
\hline IV. Bulbar-dominant phenotype & Dysphagia/dysphonia: SMN1, AR, SLC52A2, SLC52A3, VRK1, TFG (late stages), HEXB* \\
\hline $\begin{array}{l}\text { V. Multiple cranial } \\
\text { neuropathies }\end{array}$ & $\begin{array}{l}\text { Sensorineural hearing loss: SLC52A2, SLC52A3, TRPV4 } \\
\text { Vocal cord paralysis: TRPV4 }\end{array}$ \\
\hline $\begin{array}{l}\text { VI. Neuro-ophthalmological } \\
\text { disturbances }\end{array}$ & $\begin{array}{l}\text { Optic atrophy: SLC52A2, SLC52A3, } \\
\text { Pigmentary retinopathy: SLC52A2, SLC52A3, }\end{array}$ \\
\hline $\begin{array}{l}\text { VII. Other neurological or } \\
\text { neuromuscular compromise }\end{array}$ & $\begin{array}{l}\text { Cerebellar ataxia: SLC52A2, SLC52A3, HEXA, HEXB, GM2A, VRK1 } \\
\text { Postural tremor/polyminimyoclonus: VAPB, AR, TFG, SMN1, HEXB } \\
\text { Parkinsonism/Dystonia: HEXA, HEXB, GM2A } \\
\text { Myoclonus/PME: ASAH1, HEXA } \\
\text { Cognitive decline: HEXA, HEXB, SLC52A2*, SLC52A3* } \\
\text { Intellectual disability:VRK1, EXOSC3, EXOSC8, ASAH1 } \\
\text { Dysautonomia:VAPB, AR;/GHMBP2 } \\
\text { Pyramidal signs: SETX, SLC52A2*, SLC52A3*,VAPB* }\end{array}$ \\
\hline VIII. Neuroimaging findings & $\begin{array}{l}\text { Pontocerebellar hypoplasia: VRK1, EXOSC3, EXOSC8 } \\
\text { Cerebellar atrophy: SLC52A2, SLC52A3, HEXA, HEXB, GM2A, TK2* } \\
\text { Hypomyelination: EXOSC8 }\end{array}$ \\
\hline $\begin{array}{l}\text { IX. Associated } \\
\text { neurophysiological findings }\end{array}$ & $\begin{array}{l}\text { Reduced SNAP amplitude:AR, TFG, SLC52A2, SLC52A3 } \\
\text { Pseudo-myotonic discharges: SMN1*,TFG* }\end{array}$ \\
\hline X. Respiratory compromise & $\begin{array}{l}\text { Diaphragmatic involvement: IGHMBP2, LAS1L, ASAH1, SMN1, TK2* } \\
\text { Restrictive lung disease: UBA1, SMN1, GLE1, TK2* }\end{array}$ \\
\hline XI. Miscellaneous & $\begin{array}{l}\text { Multiple contracture/arthrogryposis multiplex: GLE1, UBA1, BICD2, DYNC1H1, TRPV4, SMN1* } \\
\text { Pes cavus, pes planus: DYNC1H1, BICD2, AR, SLC52A2*, SLC52A3*, TFG* } \\
\text { Diabetes and other endocrine diseases: AR, TFG } \\
\text { Cardiomyopathy: LMNA, AR } \\
\text { High serum CK levels: TFG, AR, VAPB, SMN1, TRPV4*, TK2* } \\
\text { Worse prognosis (early death): SMN1, VRK1, EXOSC3, EXOSC8, GLE1, UBA1, TK2* } \\
\text { Ancestry (family origin): Japan, Taiwan, South Korea (TFG, AR); Brazilian (VAPB); Finland (CHCHD10) }\end{array}$ \\
\hline
\end{tabular}

AD: autosomal dominant; AR: autosomal recessive; CK: creatine kinase; LGMW: limb-girdle muscular weakness; PME: progressive myoclonic epilepsy; SMA: spinal muscular atrophy; SNAP: sensory nerve action potential; XLR: X-linked recessive; * rare finding or rare presentation. All gene symbols are presented in italics.

X-linked spinal and bulbar muscular atrophy (SBMA) or Kennedy's disease (MIM \#313200) is an adult-onset X-linked recessive neurodegenerative disorder related to abnormal pathological (CAG) trinucleotide repeat expansion (generally 38-68 CAGs repeats; normal: 11-32 CAGs) in exon 1 in the $A R$ gene (Xq12), coding the androgen receptor. Toxic gain of function with polyglutamine repeats and truncated protein formation are associated with neurodegeneration pathogenesis. SBMA is the most common non-5q SMA phenotype worldwide, despite higher prevalence rates in Japan and western Finland due to founder effects ${ }^{16,17,18,19,20}$. Up to $2 \%$ of all patients misdiagnosed with ALS have SBMA. Men generally present after the fourth to sixth decade of life with dysphagia, dysphonia, perioral myofasciculations, cramps, fasciculations in the upper limbs and tongue, and longstanding proximal and symmetrical crural or brachial paraparesis (evolving to quadriparesis) and associated primary myopathy ${ }^{16,17,18,19,20}$. It is classically associated with endocrinopathies (hypogonadism, diabetes mellitus or glucose intolerance, osteopenia, testicular atrophy, oligospermia, and impaired spermatogenesis), gynecomastia, dyslipidemia with nonalcoholic fatty liver disease, risk of cardiac arrhythmia (e.g., Brugada syndrome), and rarely with left ventricular hypertrabeculation/non-compaction cardiomyopathy. Postural and intention tremor involving the hands and distal portion of the upper limbs may occur and presents with characteristics similar to essential tremor, including alcohol and beta-blocker responsiveness. Respiratory failure and 
(A)
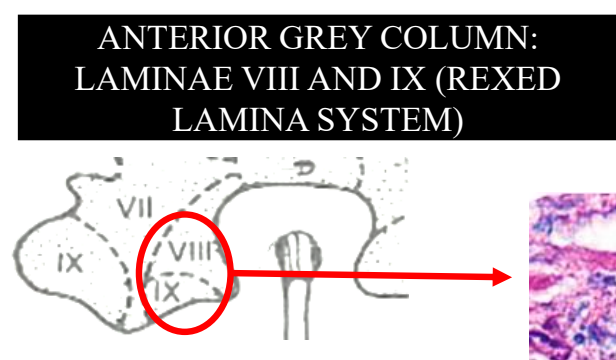

\section{EXTRAFUSAL ALPHA MOTOR} NEURON

(B)

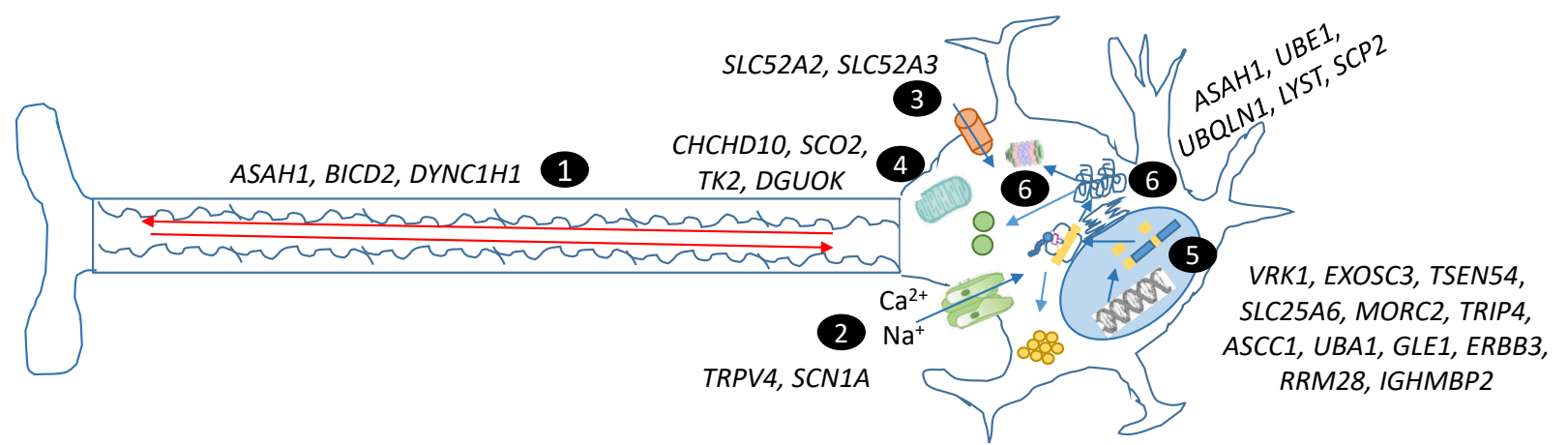

1. Defects of axonal transport and cytoskeletal dynamics (e.g., ASAH1, BICD2, DYNC1H1); 2. Primary defects of ion channels (e.g., TRPV4, SCN1A); 3. Primary defects of vitamin receptors (e.g., SLC52A2, SLC52A3); 4. Dysfunction of neuronal mitochondrial energy production and inner structure (e.g., CHCHD10, SCO2, TK2, DGUOK); 5. Defects of neuronal splicing, DNA and protein translation and transcription, and RNA processing (e.g., VRK1, EXOSC3, TSEN54, SLC25A6, MORC2, TRIP4, ASCC1, UBA1, GLE1, ERBB3, RRM28, IGHMBP2); 6. Defects of pathways of protein aggregation, misfolding, and degradation (e.g., ASAH1, UBA1, UBQLN1, LYST, SCP2).

Figure 1. Lower motor neuron anatomical location and structure (A) and non-5q SMA pathophysiological mechanisms (B).

even vocal cord palsy are eventually observed in late stages of disease. Episodic laryngeal stridor and sudden acute respiratory failure may be observed especially during intercurrent infections ${ }^{16,17,18,19,20}$.

Genetic testing by fragment analysis of $A R$ gene for pathological CAG repeat expansions is the gold standard procedure for definite diagnosis of SBMA ${ }^{16,17,18,19,20}$. There is a wellestablished phenomenon of inverted correlation between age of onset and the length of the CAG repeat expansion with marked earlier age at onset in patients with longer repeats. Serum creatine kinase level is commonly mild to moderately elevated, ranging from 650 to $1500 \mathrm{Ui} / \mathrm{L}$. Muscle biopsy commonly discloses both classic neurogenic and myopathic findings, including vacuolar myopathy, central nuclei, tubular aggregates, and myofibrillar disorganization ${ }^{16,17,18}$. Neurophysiological testing usually shows markedly reduced SNAP (sensory nerve action potentials) amplitude with subclinical sensory symptoms and chronic denervation changes, primarily in bulbar and cervical myotomes. Sensory symptoms with distal dysesthesias in the lower limbs and postural tachycardia are more commonly associated with early-onset cases $^{16,17,18}$. Muscle imaging studies have emerged recently in the study of neurogenic conditions such as SBMA and are a potential resource for diagnosis, follow-up of patients ${ }^{21}$, and differential diagnosis with other chronic neurodegenerative conditions such as $\mathrm{ALS}^{22}$. Plasma pNfH levels can also give important clues in the differentiation from bulbaronset ALS, depending on clinical stage, and may become a possible diagnostic or prognostic biomarker for future stud$i^{23}$. Symptomatic heterozygous females with very lateonset ( seventh to eight decade) may present with mild clinical course, cramps, and tongue fasciculations with raised serum creatine kinase (CK) levels ${ }^{17,19,20}$. Long-term treatment with leuprorelin (11.25 mg per dose, once each 12 weeks, subcutaneous use, for up to 84 months) in patients with SBMA during a natural history-controlled study has disclosed a tendency to decrease the progression of the clinical course of motor and bulbar dysfunction, according to ALSFRS-R (ALS Functional Rating Scale-Revised) total score and Limb Norris Score, as well as clinical improvement of dysphagia and lesser occurrence of aspiration pneumonia and death ${ }^{24}$. Leuprorelin is currently a potential therapeutic candidate for patients with mild to moderate motor and bulbar compromise, especially in patients at early clinical stages and without severe respiratory involvement ${ }^{20}$; however, double-blind clinical randomized studies are still necessary. 5alpha-reductase inhibitors have also been studied in few case reports and small case series without marked clinical improvement ${ }^{25}$. A double-blind randomized placebo-controlled trial using intravenous IGF-1 mimetics provided stable muscle volumes during the study period but without improvement of motor function and muscle strength ${ }^{26}$.

In addition, a study reposts a Japanese family with autosomal dominant progressive spinal and bulbar muscular atrophy associated with gynecomastia, upgaze ocular abnormalities, postural tremor, and dysphonia, mimicking 
features of Kennedy's disease but with paternal transmission and without pathogenic CAG repeat expansions in $A R$ gene. No abnormal autonomic and sensory changes are reported ${ }^{27}$.

\section{Finkel type spinal muscular atrophy}

Finkel type SMA (MIM \#182980) is a rare late-onset neurodegenerative lower MND typically found in the Brazilian population, allelic to familial ALS type 8 and linked to the heterozygous pathogenic variant p.Pro56Ser in the VAPB (20q13.32) gene, coding the VAMP-associated membrane protein type B. This autosomal dominant adult-onset SMA was originally described by Dr. Nunjo Finkel in 1962, after the analysis of four Brazilian patients (from Guarani town, located in the Zona da Mata, within the state of Minas Gerais) which presented with slowly progressive lower limb weakness, mainly involving the pelvic girdle ${ }^{28}$. It is a long-standing symmetrical lower MND associated with amyotrophy, areflexia, cramps, and postural tremor in distal upper limbs. Most cases present during the third to sixth decade of life with proximal weakness in the lower limbs, evolving after 2 to 3 decades to the upper limbs and respiratory muscle groups. There is marked involvement of abdominal muscle groups with weakness and hypotonia and hyperlordosis ${ }^{29,30,31,32}$. Mildly raised serum CK levels are commonly observed. Needle EMG studies commonly show chronic denervation and reinnervation involving cervical, thoracic, and lumbosacral myotomes, but may also disclose acute denervation, more commonly in earlier onset cases in the third decade of life. Cases with associated upper motor neuron signs generally have more rapid and severe clinical course in the spectrum of familial ALS type 8. Dysautonomic features have also been observed, including chronic constipation, abnormal sudomotor function, sexual dysfunction, sporadic spontaneous choking fits, and suffocation $28,29,30,31,32$.

\section{Jokela type spinal muscular atrophy}

Jokela type SMA (MIM \#615048) is an autosomal dominant late-onset lower MND described in the last years associated with mitochondrial dysfunction secondary to heterozygous pathogenic variants in the CHCHD10 (22q11.23) gene. It has been predominantly described in Finnish families with heterozygous pathogenic variant p.Gly66Val probably due to the founder effect. Most cases start with motor symptoms after the third to fifth decade of life, while cramps and fasciculations may be observed since the third decade of life. It is a pure symmetrical slowly progressive late-onset motor neuronopathy with proximal predominance, diffuse areflexia, fasciculations, myalgia, and painful cramps with only mild bulbar compromise. Head drop and drop attack-like episodes may also be observed and do not correlate with clinical severity ${ }^{33,34,35,36,37}$. Other family members may present with other signs of mitochondrial disease, including eyelid ptosis, cerebellar ataxia, frontotemporal dementia, ALS, atypical parkinsonism, inherited axonal neuropathy, pes cavus or pes planus, hammertoes, bilateral sensorineural hearing loss, and mitochondrial myopathy ${ }^{36}$. Amyotrophy is more commonly found after two to three decades of clinical involvement ${ }^{34,35,36,37}$, but calf pseudohypertrophy may be also observed ${ }^{33}$. There is marked intrafamilial clinical variability in carriers of p.Gly66Val pathogenic variant, ranging from inherited sensorimotor axonal neuropathy, SMA, and ALS presentation. Upper motor neuron involvement, FTD, and cerebellar ataxia are more commonly observed in patients with the p.Ser59Leu pathogenic variant. Muscle biopsy studies disclose chronic neurogenic findings, distinct large fiber type grouping with non-atrophic type IIA muscle fibers, group atrophy, small groups of highly atrophic rounded type IIA fibers, mitochondrial dysfunction findings, and up to $60 \%$ with p62 or TDP-43 positive vacuoles. Muscle MRI shows diffuse fatty degenerative changes, markedly bilateral and in medial gastrocnemius. Serum CK levels are commonly raised up to 8 times above the upper limit of normality ${ }^{33,32,33,34,35,36,37,38,39,40}$

\section{TRPV4-associated scapuloperoneal syndrome}

TRPV4-associated scapuloperoneal syndrome or New England type SMA (MIM \#181405) in most cases presents as autosomal dominant early-onset SMA with slowly progressive neurogenic scapuloperoneal weakness and amyotrophy and laryngeal palsy, mimicking features of facioscapulohumeral muscular dystrophy. Most cases present with non-progressive very early-onset or congenital-onset weakness and knee and ankle contractures with mildly raised serum CK levels. Males are commonly more severely affected than women. Skeletal dysplasia may be also observed in very early-onset cases ${ }^{11,41,42}$. However, late adult-onset cases have been also described with TRPV4 (12q24.11) gene mutations and related to both distal and proximal predominant phenotypes. Although associated with missense pathogenic variants in autosomal genes, phenotypes become more severe and appear earlier in later generations. Key differential diagnoses include distal SMA and axonal Charcot-Marie-Tooth (CMT) disease. Allelic conditions include CMT type 2C and rare osteomuscular dysplasia and malformation ${ }^{41,42}$.

\section{Okinawa type spinal muscular atrophy}

Okinawa type SMA or hereditary sensory and motor proximal neuronopathy (previously known as proximal CMT) (MIM \#604484) is associated with heterozygous pathogenic variants in the TFG (3q12.2) gene and originates slowly progressive SMA with proximal and lower limb predominance, starting in early adulthood and commonly associated with tremor, cramps, and late sensory neuronopathy. Cramps and fatigue commonly precede the onset of proximal muscle weakness and fasciculations involve the truncal and distal portion of the upper limbs. Most typical presentations are associated with the heterozygous pathogenic variant p.Pro285Leu. It is commonly associated with glucose 
intolerance, diabetes mellitus, dyslipidemia, and mildly raised serum creatine kinase levels (300-1000 Ui/L). Pes cavus and mild scoliosis are rarely observed ${ }^{43,44}$. Myotonic-like phenomenon and myotonic discharges may also be rarely observed. Despite the occurrence of less severe and later bulbar compromise in Okinawa type SMA, this neurodegenerative disorder should be considered in the differential diagnosis of Kennedy's disease especially in the context of patients with negative genetic testing and autosomal dominant pattern of inheritance, similar clinical phenotypes, marked compromise of sensory nerve action potential amplitude, and positive epidemiologic and family histories for Okinawa's ancestry. Its major representative ethnic group of patients is from Japan (from Kansai and Okinawa region), South Korea, Taiwan, and Brazilian patients from Japanese ancestry. Allelic conditions include autosomal recessive hereditary spastic paraplegia type 57 (SPG57) and extraskeletal myxoid chondrosarcoma ${ }^{43,44,45,46}$.

\section{Adult-onset GM2 gangliosidosis}

GM2 gangliosidosis is a complex and classical inherited neurometabolic group of disorders resulting from inborn errors of metabolism with beta-hexosaminidase A or B deficiencies. GM2 gangliosidosis results from mutations in the coding genes of alpha subunit (HEXA), beta subunit (HEXB), or GM2 gangliosidosis coactivator (GM2A) of hexosaminidases A and B, leading to abnormal lysosomal storage of neuronal glycosphingolipids. Neurological presentations of GM2 gangliosidosis include infantile, juvenile, and adult late-onset cases. Regarding its biochemical basis, three neurometabolic phenotypes can be recognized: Tay-Sachs disease (isolated deficiency of hexosaminidase A), Sandhoff disease (combined deficiency of hexosaminidases A and B), and GM2 activator deficiency. Despite the existence of atypical late-onset Tay-Sachs disease of the adult (MIM \#272800) presenting with isolated cerebellar ataxia or pure symmetrical slowly progressive SMA resulting from homozygous or compound heterozygous mutations in the HEXA (15q23) gene or GM2A (5q33.1) gene in the GM2 activator deficiency (MIM \#272750), late-onset lower MND presentation has been more widely described in association with adult-onset Sandhoff disease (MIM \#268800) with compound heterozygous or homozygous pathogenic variants in the HEXB (5q13.3) gene ${ }^{47}$. It is uncommon in late-onset cases of both Tay-Sachs disease and Sandhoff disease the occurrence of cherry-red spots, seizures, or the progressive myoclonic epilepsy phenotype. Late-onset cases may be clinically undistinguishable from juvenile ALS or SMA type IIIb/IV, however more commonly involves triceps brachii and intrinsic muscles of the hand in the upper limbs. Late-onset GM2 gangliosidosis may be also associated with saccadic dysmetria, abnormal vertical and horizontal pursuit, low angular vestibulo-ocular reflex, cerebellar ataxia, cognitive decline, parkinsonism, and cerebellar cognitive affective syndrome during disease course ${ }^{47}$.
Pyramidal release signs may be observed in late-onset cases, but usually with associated cerebellar ataxia or lower MND. Neuropsychiatric disturbances including psychosis, anxiety, and depression are frequently observed, even in early stages of disease. Rare adult-onset presentations of Sandhoff disease with pure lower motor neuron (LMN) include brachial amyotrophic diplegia ${ }^{48}$ and bulbospinal neuronopathy with bilateral facial weakness, dysarthria, dysphagia, and postural tremor, mimicking features of Kennedy's disease ${ }^{49}$. Neuroimaging studies generally disclose cerebellar atrophy (even in cases without cerebellar ataxia), variable cortical atrophy, and absence of thalamic signal changes commonly observed in infantile-onset cases. Needle EMG discloses chronic diffuse denervation and reinnervation signs, while nerve conduction studies show moderate reduction of SNAP amplitudes. General prognosis is better in late-onset cases if compared to infantile and juvenile-onset presentations, commonly with normal life spam ${ }^{12,47,49,50,51}$.

\section{LMNA-associated spinal muscular atrophy}

Adult-onset proximal SMA with cardiac involvement results from heterozygous mutations in the LMNA (1q22) gene, coding the prelamin $\mathrm{A} / \mathrm{C}$, and is characterized by autosomal dominant SMA starting between 35 and 65 years of age, with symmetrical, slowly progressive and proximal predominance, associated lately with variable degrees of cardiomyopathy, including atrioventricular blocks, atrial fibrillation, and dilated cardiomyopathy. Serum CK levels are commonly unremarkable in most cases. Needle EMG includes mixed chronic denervation and reinnervation findings and mild myopathic features, while targetoid-fibers and type grouping are commonly observed in muscle biopsy. More than 10 different allelic clinical conditions have been described, including autosomal dominant or recessive Emery-Dreifuss muscular dystrophy, congenital muscular dystrophy, limb-girdle muscular dystrophy type 1B, Hutchinson-Gilford progeria, CMT type 2B1, and different syndromic and non-syndromic restrictive or dilated cardiomyopathies ${ }^{11,52,53}$.

\section{Hereditary motor neuronopathy with pyramidal features}

Hereditary motor neuronopathy with pyramidal features (also called SMA with retained reflexes) is a rare neurodegenerative condition due to heterozygous pathogenic variants in the SETX gene (9q34.13), coding neuronal senataxin, and is associated with autosomal dominant slowly progressive symmetrical SMA with distal and proximal involvement combined with brisk tendon reflexes or pyramidal release signs. Bulbar and cognitive dysfunction are not observed until very late stages of disease. Allelic conditions include familial ALS type 4 (juvenile ALS type 4) and oculomotor apraxia type 2. Some authors include both juvenile ALS type 4 and hereditary motor neuronopathy with pyramidal features as overlapping and undistinguishable clinical conditions ${ }^{1,54,55}$. 
Adult-onset atypical spinal muscular

\section{atrophy with lower extremity predominance}

SMA with lower extremity predominance type 1 (SMALED1) (MIM \#158600) is a rare early-onset slowly progressive SMA that presents with marked proximal and lower limb predominance. Distal involvement with pes planus or cavus may be also observed, especially in early-onset cases. Cognitive compromise, delayed motor milestones and polymicrogyria and other neuronal migration defects are commonly observed in early-onset cases. However, atypical adultonset and juvenile-onset cases have been also associated with pathogenic variants in the DYNC1H1 gene (14q32.31) and with slowly progressive clinical course, similar to extremely rare adult-onset presentations of autosomal dominant SMALED type 2A (MIM \#615290) due to BICD2 gene (9q22.31) with joint contractures ${ }^{56,57,58,59}$. Late-onset cases with proximal upper limb involvement have also been described. There is marked clinical overlap with CMT phenotype, and some patients remain misdiagnosed with an inherited neuropathy during decades until a definite neurophysiological study discloses almost normal SNAPs. Allelic conditions include CMT type 2O, cortical neuronal migration defect with intellectual disability and congenital MND with isolated cortical malformation ${ }^{56,57,58,59}$.

\section{Late-onset primary riboflavin}

transporter deficiency (SLC52A2, SLC52A3)

Late-onset (or adult form) of both Fazio-Londe disease and Brown-Vialetto-van Laere syndrome (MIM \#211530, \#614707) are typical clinical presentations of primary riboflavin transporter deficiency in the gut, central nervous system, or blood-brain barrier due to homozygous or compound heterozygous pathogenic variants in the SLC52A2 (8q24.3) or SLC52A3 (20p13) genes ${ }^{60,61}$. Despite global distribution with familial aggregates in Arabic, Scottish, Italian, Lebanese, and Pakistani families and occurrence in both sexes, there is female predominance in sporadic and familial cases. Both conditions typically give rise to autosomal recessive SMA with bulbar, facial and symmetrical and proximal involvement of the upper limbs, sometimes associated with cerebellar ataxia, sensorimotor axonal neuropathy, scoliosis, optic atrophy, retinitis pigmentosa, psychiatric disturbances, and sensorineural deafness (exclusively associated with Brown-Vialetto-van Laere syndrome and commonly preceding motor symptom-onset), evolving lately with dropped head syndrome and severe respiratory insufficiency ${ }^{60,61,62,63}$. Late-onset phenotypes are associated with slowly progressive clinical course, whilst early adulthood phenotypes present commonly with more rapidly progressive bulbar symptoms. However, rapidly progressive bulbar and facial involvement responsive to riboflavin supplementation has been reported in adult-onset cases, mimicking bulbar-onset ALS. The occurrence of multiple lower cranial nerve palsies (mainly VII, IX, and XII cranial nerves) gives a major clue to consider riboflavin transporter defects as a possible diagnosis ${ }^{60,61,62,63}$. The main differential diagnosis for most cases include juvenile or young-onset bulbar-onset ALS, sporadic progressive bulbar palsy (especially in female cases), Madras MND, FOSMN (facial-onset sensory and motor neuronopathy) syndrome, Finnish type hereditary amyloidosis (amyloid cranial neuropathy with lattice corneal dystrophy type II), Worster-Drought syndrome, Boltshauser syndrome and Nathalie syndrome $e^{60,61,62,63}$. Riboflavin transporter defects are potentially treatable inherited neurometabolic disorders, which can be associated with variable degrees of clinical and neurophysiological response to high therapeutic doses of oral riboflavin supplementation (10-20 mg/kg/day). Regarding metabolic profile studies, acylcarnitine profiles commonly present abnormal testing with similar patterns observed also in MADD (multiple acyl-CoA dehydrogenase deficiency) or glutaric aciduria type II and sometimes with secondary carnitine deficiency ${ }^{12,60,61,62,63}$.

\section{Lower motor neuron disease with respiratory failure associated with MAPT gene mutations}

This autosomal dominant tauopathy was described in large non-consanguineous Italian kindred, resulting from a heterozygous pathogenic variant p.Asp348Gly in the MAPT gene (17q21.31), coding the microtubule-associated protein Tau, involved with axonal transport and microtubule functions. All patients presented with adult-onset proximal symmetric weakness of the upper limbs and prominent early respiratory failure. None of the patients presented with signs suggestive of frontotemporal lobar degeneration or its variants ${ }^{64}$. This same gene mutation was identified also in an Italian female patient with LMN-dominant ALS with long-lasting disease course, mild Parkinsonism, and early respiratory failure ${ }^{65}$. This clinical-genetic subtype added intraneuronal tau degradation and its related pathways to the pathophysiological understanding of lower motor neuron degeneration and the potential role of neurofibrillary tangles with hyperphosphorylated tau protein as potential neuropathological biomarkers of this non-5q SMA. Neuropathological studies disclosed accumulated phosphorylated tau protein in the surviving lower motor neurons and reduction of neurite length and arborization from alphamotoneuron. Allelic disorders include Frontotemporal lobar degeneration with MND or Parkinsonism, and progressive supranuclear palsy $\mathrm{y}^{6,65}$.

\section{Late-onset spinal muscular atrophy associated with progressive myoclonic epilepsy due to acid ceramidase deficiency}

Autosomal recessive non-5q SMA associated with $\mathrm{N}$-acylsphingosine amidohydrolase 1 (acid ceramidase) deficiency is due to homozygous or compound heterozygous pathogenic variants in $A S A H 1$ gene (8p22). Most cases have onset during the first two decades of life, generally with 
proximal lower limb weakness and hypotonia due to lower motor neuron disease, followed by upper limb involvement, postural tremor, myoclonus and progressive myoclonic epilepsy during the second or third decade of life. Poliarticular arthritis, eyelid myoclonic status epilepticus, absence epilepsy with atonic seizures, and sensorineural deafness may also be observed. Myoclonic epilepsy is commonly resistant to conventional drug therapy. EEG generally discloses subcortical myoclonic epileptic discharges sensitive to hyperventilation. Atypical presentations with pure lower motor neuron syndrome or pure myoclonic epilepsy have been also identified. Mild adult-onset presentations without seizures or myoclonus have been also described. Allelic conditions include Farber lipogranulomatosis ${ }^{12,66}$.

\section{Late-onset spinal muscular atrophy with respiratory distress due to IGHMBP2 mutations}

This autosomal recessive presentation commonly originates in childhood with diaphragmatic palsy, dysautonomic features, sensory polyneuropathy, and symmetrical distal and proximal SMA due to compound heterozygous or homozygous pathogenic variants in the $I G H M B P 2$ gene (11q13.3), coding the helicase immunoglobulin mu DNA-binding protein 2. Neonatal presentations are commonly fatal during the first year of life. Late-onset phenotypes have been rarely described with mild distal and proximal motor involvement, but in some cases associated with early scoliosis and diaphragmatic palsy. Important intrafamilial variability is observed in some cases, especially in those with associated sensorimotor axonal polineuropathy. Allelic conditions include CMT type 2S, distal hereditary motor neuronopathy type VI, and infantile-onset SMARD ${ }^{67,68}$.

\section{A practical diagnostic approach and flowchart for suspected cases of adult-onset non-5Q proximal spinal muscular atrophy}

Adult-onset non-5q SMA is a complex and genetically heterogeneous group of neurodegenerative and neurometabolic disorders. A diagnostic flowchart can be applied to suspected cases of adult-onset proximal SMA (Figure 2) for a detailed and more precise symptom and sign-based approach to a definite diagnosis of these complex clinical conditions ${ }^{9,10,11,12,14}$. Clinical, laboratorial, neurophysiological, and neuroimaging clues (Table 4) are the best way to rule out other important differential diagnoses in LMN syndrome (pure SMA and SMA-plus phenotypes) and provide key information for the best cost-effective diagnostic work-up $p^{3,9,10,11,12,14}$. Due to the complex expanding genetic and clinical spectrum of non-5q proximal SMA, next-generation sequencingbased approaches (or massively parallel sequencing technologies) including whole-exome sequencing or targeted sequencing panels represent the main definitive diagnostic methods for most cases ${ }^{13}$, although specific genetic testing with Sanger sequencing, hotspot analysis, and single gene sequencing is still essential in certain clinical settings (e.g., highly specific phenotypes or populations with specific variants due to founder effects $)^{9,10,11,14}$. A proper definite diagnosis of the underlying genetic basis is essential to provide specific

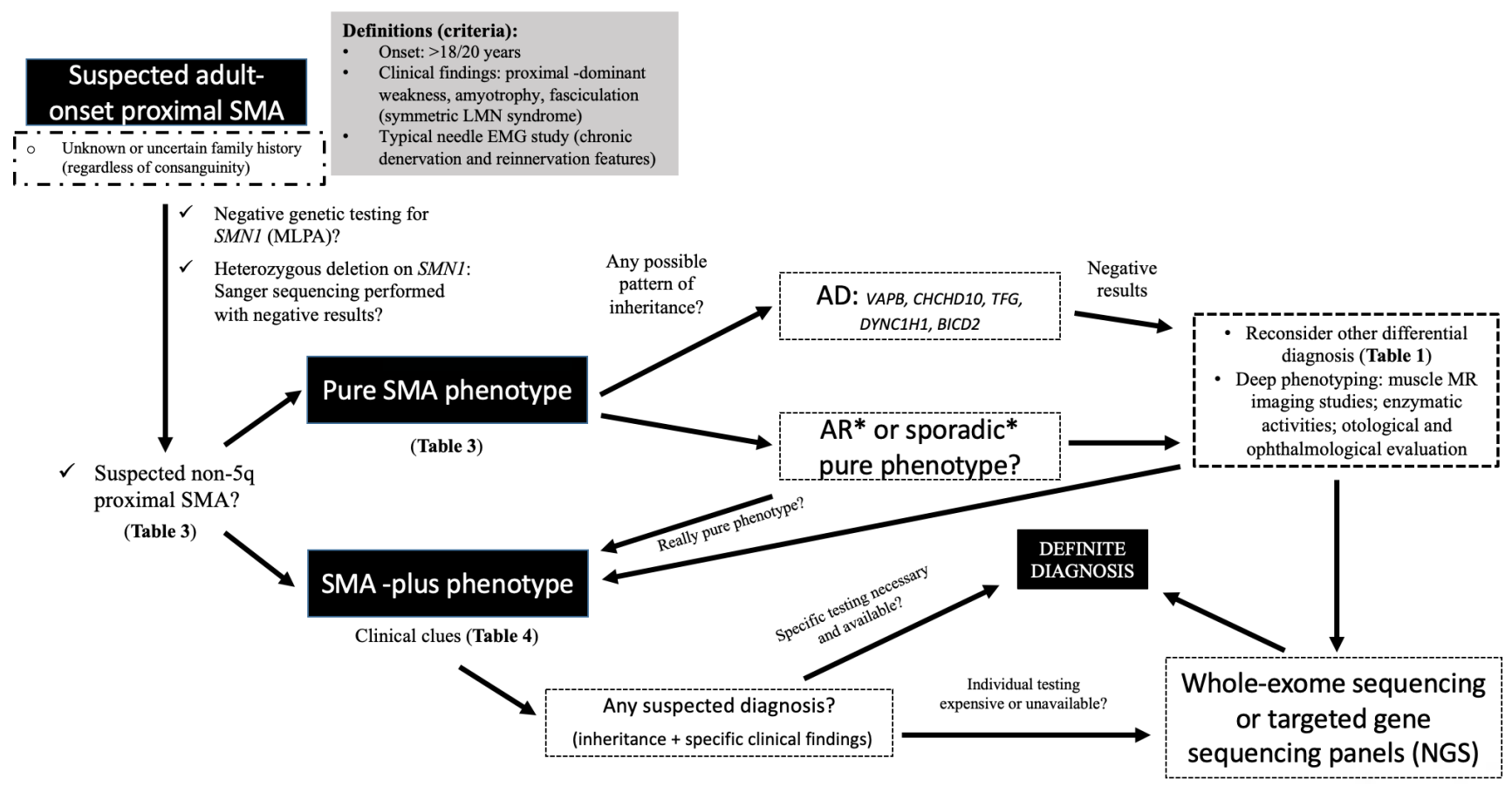

AD: autosomal dominant;AR: autosomal recessive; EMG: electromyography; LMN: lower motor neuron; MLPA: Multiplex Ligation-dependent Probe Amplification; NGS: next-generation sequencing; SMA: spinal muscular atrophy.

Figure 2. Diagnostic flowchart for suspected cases of adult-onset proximal spinal muscular atrophy. 
disease-modifying therapies, especially at early stages of the clinical course, aiming better prognosis and more significant clinical outcomes.

Late adult-onset SMA is a new expanding group of inherited neurodegenerative disorders in clinical practice which arise in the context of a major differential diagnosis of adult lower MND with pure motor phenotypes or complex systemic and neurological phenotypes. Proper evaluation and diagnosis of such group of diseases is essential as many of them present with specific potentially treatable pathophysiological dysfunction which can improve motor and non-motor symptoms and signs.

\section{References}

1. Souza PVS, Pinto WBVR, Chieia MAT, Oliveira ASB. Clinical and genetic basis of familial amyotrophic lateral sclerosis. Arq NeuroPsiquiatr. 2015 Dec;73(12):1026-37. https://doi.org/10.1590/0004282X20150161

2. Garg N, Park SB, Vucic S, Yiannikas C, Spies J, Howells J, et al. Differentiating lower motor neuron syndromes. J Neurol Neurosurg Psychiatry. 2017 Jun;88(6):474-83. https://doi.org/10.1136/jnnp2016-313526

3. Benarroch L, Bonne G, Rivier F, Hamroun D. The 2021 version of the gene table of neuromuscular disorders (nuclear genome). Neuromuscul Disord. 2020 Dec;30(12):1008-48. https://doi. org/10.1016/j.nmd.2020.11.009

4. Pinto WBVR, Debona R, Nunes PP, Assis ACD, Lopes CG, Bortholin T, et al. Atypical Motor Neuron Disease variants: still a diagnostic challenge in Neurology. Rev Neurol (Paris). 2019 Apr;175(4):221-32. https://doi.org/10.1016/j.neurol.2018.04.016

5. Arnold WD, Kassar D, Kissel JT. Spinal muscular atrophy: diagnosis and management in a new therapeutic era. Muscle Nerve. 2015 Feb;51(2):157-67. https://doi.org/10.1002/mus.24497

6. Kolb SJ, Kissel JT. Spinal muscular atrophy. Neurol Clin. 2015 Nov;33(4):831-46. https://doi.org/10.1016/j.ncl.2015.07.004

7. Turner MR, Barnwell J, Al-Chalabi A, Eisen A. Young-onset amyotrophic lateral sclerosis: historical and other observations. Brain. 2012 Sep;135(Pt 9):2883-91. https://doi.org/10.1093/brain/ aws 144

8. Farrar MA, Kiernan MC. The genetics of Spinal Muscular Atrophy: progress and challenges. Neurotherapeutics. 2015 Apr;12(2):290302. https://doi.org/10.1007/s13311-014-0314-x

9. Zerres K, Rudnik-Schöneborn S. 93 ${ }^{\text {rd }}$ ENMC international workshop: non-5q spinal muscular atrophies (SMA) - clinical picture (6-8 April 2001, Naarden, The Netherlands). Neuromuscul Disord. 2003 Feb;13(2):179-83. https://doi.org/10.1016/s0960-8966(02)00211-0

10. Wee CD, Kong L, Sumner CJ. The genetics of spinal muscular atrophies. Curr Opin Neurol. 2010 Oct;23(5):450-8. https://doi. org/10.1097/WCO.0b013e32833e1765

11. Peeters K, Chamova T, Jordanova A. Clinical and genetic diversity of SMN1-negative proximal spinal muscular atrophies. Brain. 2014 Nov;137(11):2879-96. https://doi.org/10.1093/brain/awu169

12. Souza PVS, Bortholin T, Naylor FGM, Chieia MAT, Pinto WBVR, Oliveira ASB. Motor neuron disease in inherited neurometabolic disorders. Rev Neurol (Paris). 2018 Mar;174(3):115-24. https://doi.org/10.1016/j. neurol.2017.06.020

13. Karakaya M, Storbeck M, Strathmann EA, Vedove AD, Hölker I, Altmueller $J$, et al. Targeted sequencing with expanded gene profile enables high diagnostic yield in non-5q-spinal muscular atrophies. Hum Mutat. 2018 Sep;39(9):1284-98. https://doi.org/10.1002/ humu. 23560

14. Darras BT. Non- $5 q$ spinal muscular atrophies: the alphanumeric soup thickens. Neurology. 2011 Jul;77(4):312-4. https://doi. org/10.1212/WNL.0b013e3182267bd8
15. Kennedy WR, Alter M, Sung JH. Progressive proximal spinal and bulbar muscular atrophy of late onset. A sex-linked recessive trait. Neurology. $1968 \mathrm{Jul} ; 18(7): 671-80$. https://doi.org/10.1212/wnl.18.7.671

16. Grunseich C, Fischbeck KH. Spinal and bulbar muscular atrophy. Neurol Clin. 2015 Nov;33(4):847-54. https://doi.org/10.1016/j. ncl.2015.07.002

17. Manzano R, Sorarú G, Grunseich C, Fratta P, Zuccaro E, Pennuto $M$, et al. Beyond motor neurons: expanding the clinical spectrum in Kennedy's disease. J Neurol Neurosurg Psychiatry. 2018 Aug;89(8):808-12. https://doi.org/10.1136/jnnp-2017-316961

18. Querin G, Soraru G, Pradat PF. Kennedy disease (X-linked recessive bulbospinal neuronopathy): a comprehensive review from pathophysiology to therapy. Rev Neurol (Paris). 2017 May;173(5):32637. https://doi.org/10.1016/j.neurol.2017.03.019

19. Breza M, Koutsis G. Kennedy's disease (spinal and bulbar muscular atrophy): a clinically oriented review of a rare disease.J Neurol. 2019 Mar;266(3):565-73. https://doi.org/10.1007/s00415-018-8968-7

20. Pradat PF, Bernard E, Corcia P, Couratier P, Jublanc C, Querin G, et al. The French national protocol for Kennedy's disease (SBMA): consensus diagnostic and management recommendations. Orphanet J Rare Dis. 2020 Apr 10;15(1):90. https://doi.org/10.1186/ s13023-020-01366-z

21. Dahlqvist JR, Oestergaard ST, Poulsen NS, Thomsen C, Vissing $J$. Refining the spinobulbar muscular atrophy phenotype by quantitative MRI and clinical assessments. Neurology. 2019 Feb;92(6):e548-e559. https://doi.org/10.1212/ WNL.0000000000006887

22. Klickovic U, Zampedri L, Sinclair CDJ, Wastling SJ, Trimmel K, Howard RS, et al. Skeletal muscle MRI differentiates SBMA and ALS and correlates with disease severity. Neurology. 2019 Aug;93(9):e895-e907. https://doi.org/10.1212/ WNL.0000000000008009

23. Lombardi V, Bombaci A, Zampedri L, Lu CH, Malik B, Zetterberg H, et al. Plasma pNfH levels differentiate SBMA from ALS. J Neurol Neurosurg Psychiatry. 2020 Feb;91(2):215-7. https://doi.org/10.1136/ jnnp-2019-320624

24. Hashizume A, Katsuno M, Suzuki K, Banno H, Takeuchi Y, Kawashima $M$, et al. Efficacy and safety of leuprorelin acetate for subjects with spinal and bulbar muscular atrophy: pooled analyses of two randomized-controlled trials. J Neurol. 2019 May;266(5):1211-21. https://doi.org/10.1007/s00415-019-09251-x

25. Fernández-Rhodes LE, Kokkinis AD, White MJ, Watts CA, Auh $\mathrm{S}$, Jeffries NO, et al. A randomised, placebo-controlled trial of dutasteride in spinal and bulbar muscular atrophy. Lancet Neurol. 2011 Feb;10(2):140-7. https://doi.org/10.1016/S14744422(10)70321-5

26. Grunseich C, Miller R, Swan T, Glass DJ, El Mouelhi M, Fornaro M, et al. Safety, tolerability, and preliminary efficacy of an IGF-1 mimetic in patients with spinal and bulbar muscular atrophy: a randomized, placebo-controlled trial. Lancet Neurol. 2018 Dec;17(12):1043-52. https://doi.org/10.1016/S1474-4422(18)30320-X 
27. Ikezoe K, Yoshimura T, Taniwaki T, Matsuura E, Furuya H, Yamada T, et al. Autosomal dominant familial spinal and bulbar muscular atrophy with gynecomastia. Neurology. 1999 Dec;53(9):2187-9. https://doi.org/10.1212/wnl.53.9.2187

28. Finkel N. A forma pseudomiopàtica tardia da atrofia muscular progressiva heredo-familial. Arq Neuro-Psiquiatr. 1962 Dec;20(4):307-22. https://doi.org/10.1590/S0004282X1962000400005

29. Richieri-Costa A, Rogatko A, Levisky R, Finkel N, Frota-Pessoa O. Autosomal dominant late adult spinal muscular atrophy, type Finkel. Am J Med Genet. 1981;9(2):119-28. https://doi.org/10.1002/ ajmg.1320090206

30. Nishimura AL, Mitne-Neto M, Silva HC, Richieri-Costa A, Middleton $\mathrm{S}$, Cascio D, et al. A mutation in the vesicle-trafficking protein VAPB causes late-onset spinal muscular atrophy and amyotrophic lateral sclerosis. Am J Hum Genet. 2004 Nov;75(5):822-31. https://doi. org/10.1086/425287

31. Marques VD, Marques W Jr. Neurophysiological findings of the late-onset, dominant, proximal spinal muscular atrophies with dysautonomia because of the VAPB Pro56Ser mutation. J Clin Neurophysiol. 2008 Aug;25(4):233-5. https://doi.org/10.1097/ WNP.0b013e31817ed219

32. Kosac V, Freitas MR, Prado FM, Nascimento O, Bittar C. Familial adult spinal muscular atrophy associated with the VAPB gene: report of 42 cases in Brazil. Arq Neuro-Psiquiatr. 2013 Oct;71(10):788-90. https:// doi.org/10.1590/0004-282X20130123

33. Jokela M, Penttilä S, Huovinen S, Hackman P, Saukkonen AM, Toivanen J, et al. Late-onset lower motor neuronopathy: a new autosomal dominant disorder. Neurology. $2011 \mathrm{Jul} ; 77(4): 334-40$. https://doi.org/10.1212/WNL.0b013e3182267b71

34. Penttilä S, Jokela M, Huovinen S, Saukkonen AM, Toivanen J, Lindberg C, et al. Late-onset spinal motor neuronopathy - a common form of dominant SMA. Neuromuscul Disord. 2014 Mar;24(3):259-68. https://doi.org/10.1016/j.nmd.2013.11.010

35. Müller K, Andersen PM, Hübers A, Marroquin N, Volk AE, Danzer $\mathrm{KM}$, et al. Two novel mutations in conserved codons indicate that $\mathrm{CHCHD} 10$ is a gene associated with motor neuron disease. Brain. 2014 Dec;137(Pt 12):e309. https://doi.org/10.1093/brain/awu227

36. Bannwarth S, Ait-El-Mkadern S, Chaussenot A, Genin EC, Lacas Gervais S, Fragaki K, et al. A mitochondrial origin for frontotemporal dementia and amyotrophic lateral sclerosis through $\mathrm{CHCHD} 10$ involvement. Brain. 2014 Aug;137(Pt 8):2329-45. https://doi. org/10.1093/brain/awu138

37. Penttilä S, Jokela M, Bouquin H, Saukkonen AM, Toivanen J, Udd B. Late onset spinal motor neuronopathy is caused by mutation in CHCHD10. Ann Neurol. 2015 Jan;77(1):163-72. https://doi. org/10.1002/ana.24319

38. Pasanen P, Myllykangas L, Poyhonen M, Kiuru-Enari S, Tienari PJ, Laaksovirta $\mathrm{H}$, et al. Intrafamilial clinical variability in individuals carrying the CHCHD10 mutation Gly66Val. Acta Neurol Scand. 2016 May;133(5):361-6. https://doi.org/10.1111/ane.12470

39. Penttilä S, Jokela M, Saukkonen AM, Toivanen J, Palmio J, Lähdesmäki J, et al. CHCHD10 mutations and motor neuron disease: the distribution in Finnish patients. J Neurol Neurosurg Psychiatry. 2017 Mar;88(3):272-7. https://doi.org/10.1136/jnnp-2016-314154

40. Brockmann SJ, Freischmidt A, Oeckl P, Müller K, Ponna SK, Helferich AM, et al. CHCHD10 mutations p.R15L and p.G66V cause motoneuron disease by haploinsufficiency. Hum Mol Genet. 2018 Feb;27(4):706-15. https://doi.org/10.1093/hmg/ddx436

41. Isozumi K, DeLong R, Kaplan J, Deng HX, lqubal Z, Hung WY, et al. Linkage of scapuloperoneal spinal muscular atrophy to chromosome 12q24.1-q24.31. Hum Mol Genet. 1996 Sep;5(9):1377-82. https://doi. org/10.1093/hmg/5.9.1377

42. Deng HX, Klein CJ, Yan J, Shi Y, Wu Y, Fecto F, et al. Scapuloperoneal spinal muscular atrophy and CMT2C are allelic disorders caused by alterations in TRPV4. Nat Genet. 2010 Feb;42(2):165-9. https://doi. org/10.1038/ng.509

43. Takashima H, Nakagawa M, Nakahara K, Suehara M, Matsuzaki T, Higuchi I, et al. A new type of hereditary motor and sensory neuropathy linked to chromosome 3. Ann Neurol. 1997 Jun;41(6):771-80. https://doi.org/10.1002/ana.410410613

44. Maeda K, Sugiura M, Kato H, Sanada M, Kawai H, Yasuda H. Hereditary motor and sensory neuropathy (proximal dominant form, HMSN-P) among Brazilians of Japanese ancestry. Clin Neurol Neurosurg. 2007 Nov;109(9):830-2. https://doi.org/10.1016/j.clineuro.2007.07.015

45. Patroclo CB, Lino AMM, Marchiori PE, Brotto MWI, Hirata MTA. Autosomal dominant HMSN with proximal involvement: new Brazilian cases. Arq Neuro-Psiquiatr. 2009 Sep;67(3B):892-6. https:// doi.org/10.1590/S0004-282X2009000500021

46. Campellone JV. Hereditary motor and sensory neuropathy with proximal predominance (HMSN-P). J Clin Neuromuscul Dis. 2013 Jun;14(4):180-3. https://doi.org/10.1097/CND.0b013e318286165a

47. Stephen CD, Balkwill D, James P, Haxton E, Sassower K, Schmahmann JD, et al. Quantitative oculomotor and nonmotor assessments in late-onset GM2 gangliosidosis. Neurology. 2020 Feb;94(7):e705-e717. https://doi.org/10.1212/ WNL.0000000000008959

48. Kang SY, Song SK, Lee JS, Choi JC, Kang JH. Adult Sandhoff disease with 2 mutations in the HEXB gene presenting as brachial amyotrophic diplegia.J Clin Neuromuscul Dis. 2013 Dec;15(2):47-51. https://doi.org/10.1097/CND.0000000000000014

49. Chardon JW, Bourque PR, Geraghty MT, Boycott KM. Very late-onset Sandhoff disease presenting as Kennedy disease. Muscle Nerve. 2015 Dec;52(6):1135-6. https://doi.org/10.1002/mus.24775

50. Cachon-Gonzalez MB, Zaccariotto E, Cox TM. Genetics and therapies for GM2 gangliosidosis. Curr Gene Ther. 2018;18(2):68-89. https://doi. org/10.2174/1566523218666180404162622

51. Scarpelli M, Tomelleri G, Bertolasi L, Salviati A. Natural history of motor neuron disease in adult onset GM2-gangliosidosis: a case report with 25 years of follow-up. Mol Genet Metab Rep. 2014 Jul;1:269-72. https://doi.org/10.1016/j.ymgmr.2014.06.002

52. Iwahara N, Hisahara S, Hayashi T, Kawamata J, Shimohama S. A novel lamin A/C gene mutation causing spinal muscular atrophy phenotype with cardiac involvement: report of one case. BMC Neurol. 2015 Feb;15:13. https://doi.org/10.1186/s12883-015-0269-5

53. Rudnik-Schöneborn S, Botzenhart E, Eggermann T, SenderekJ, Schoser BG, Schröder R, et al. Mutations of the LMNA gene can mimic autosomal dominant proximal spinal muscular atrophy. Neurogenetics. 2007 Apr;8(2):137-42. https://doi.org/10.1007/ s10048-006-0070-0

54. Chen YZ, Bennett CL, Huynh HM, Blair IP, Puls I, Irobi J, et al. DNA/ RNA helicase gene mutations in a form of juvenile amyotrophic lateral sclerosis (ALS4). Am J Hum Genet. 2004 Jun;74(6):1128-35. https://doi.org/10.1086/421054

55. Rudnik-Schöneborn S, Arning L, Epplen JT, Zerres K. SETX gene mutation in a family diagnosed autosomal dominant proximal spinal muscular atrophy. Neuromuscul Disord. 2012 Mar;22(3):258-62. https://doi.org/10.1016/j.nmd.2011.09.006

56. Scoto M, Rossor AM, Harms MB, Cirak S, Calissano M, Robb S, et al. Novel mutations expand the clinical spectrum of DYNC1H1associated spinal muscular atrophy. Neurology. 2015 Feb;84(7):66879. https://doi.org/10.1212/WNL.0000000000001269

57. Niu Q, Wang X, Shi M, Jin Q. A novel DYNC1H1 mutation causing spinal muscular atrophy with lower extremity predominance. Neurol Genet. 2015 Aug;1(2):e20. https://doi.org/10.1212/ NXG.0000000000000017

58. Rossor AM, Oates EC, Salter HK, Liu Y, Murphy SM, Schule R, et al. Phenotypic and molecular insights into spinal muscular atrophy due to mutations in BICD2. Brain. 2015 Feb;138(Pt 2):293-310. https:// doi.org/10.1093/brain/awu356 
59. Beecroft SJ, McLean CA, Delatycki MB, Koshy K, Yiu E, Haliloglu G, et al. Expanding the phenotypic spectrum associated with mutations of DYNC1H1. Neuromuscul Disord. 2017 Jul;27(7):607-15. https://doi. org/10.1016/j.nmd.2017.04.011

60. Bosch AM, Stroek K, Abeling NG, Waterham HR, ljlst L, Wanders RJ. The Brown-Vialetto-Van Laere and Fazio Londe syndrome revisited: natural history, genetics, treatment and future perspectives. Orphanet J Rare Dis. 2012 Oct 29;7:83. https://doi.org/10.1186/1750-1172-7-83

61. Jaeger B, Bosch AM. Clinical presentation and outcome of riboflavin transporter deficiency: mini review after five years of experience. J Inherit Metab Dis. 2016 Jul;39(4):559-64. https://doi.org/10.1007/ s10545-016-9924-2

62. Bashford JA, Chowdhury FA, Shaw CE. Remarkable motor recovery after riboflavin therapy in adult-onset Brown-Vialetto-Van Laere syndrome. Pract Neurol. 2017 Jan;17(1):53-6. https://doi. org/10.1136/practneurol-2016-001488

63. Camargos S, Guerreiro R, Bras J, Mageste LS. Late-onset and acute presentation of Brown-Vialetto-Van Laere syndrome in a Brazilian family. Neurol Genet. 2018 Feb;4(1):e215. https://doi.org/10.1212/ NXG.0000000000000215
64. Di Fonzo A, Ronchi D, Gallia F, Cribiù FM, Trezzi I, Vetro A, et al. Lower motor neuron disease with respiratory failure caused by a novel MAPT mutation. Neurology. 2014 Jun;82(22):1990-8. https://doi. org/10.1212/WNL.0000000000000476

65. Origone P, Geroldi A, Lamp M, Sanguineri F, Caponnetto C, Cabona $C$, et al. Role of MAPT in pure motor neuron disease: report of a recurrent mutation in Italian patients. Neurodegener Dis. 2018;18(56):310-14. https://doi.org/10.1159/000497820

66. Yu FPS, Amintas S, Levade T, Medin JA. Acid ceramidase deficiency: Farber disease and SMA-PME. Orphanet J Rare Dis. 2018 Jul;13(1):121. https://doi.org/10.1186/s13023-018-0845-z

67. Messina MF, Messina S, Gaeta M, Rodolico C, Damiano AMS, Lombardo F, et al. Infantile spinal muscular atrophy with respiratory distress type I (SMARD 1): an atypical phenotype and review of the literature. Eur J Paediatr Neurol. 2012 Jan;16(1):90-4. https://doi. org/10.1016/j.ejpn.2011.10.005

68. Pedurupillay CRJ, Amundsen SS, Baroy T, Rasmussen M, Blomhoff A, Stadheim BF, et al. Clinical and molecular characteristics in three families with biallelic mutations in IGHMBP2. Neuromuscul Disord. 2016 Sep;26(9):570-5. https://doi.org/10.1016/j.nmd.2016.06.457 